\section{Mapping spring canola and spring wheat using Radarsat-2 and Landsat-8 images with Google Earth Engine}

\author{
Haifeng Tian ${ }^{1,2}$, Meng Meng ${ }^{1,2}$, Mingquan $\mathrm{Wu}^{1, *}$ \\ and Zheng Niu ${ }^{1,2, *}$ \\ ${ }^{1}$ The State Key Laboratory of Remote Sensing Science, \\ Institute of Remote Sensing and Digital Earth, Chinese Academy \\ of Sciences, Beijing, China \\ ${ }^{2}$ University of Chinese Academy of Sciences, Beijing, China
}

Using remote sensing, it is difficult to accurately extract spring canola and wheat planting area with only optical images because both crops have the same growth period and similar spectral characteristics. Besides, optical images are susceptible to cloud contamination. Synthetic aperture radar is sensitive to canopy structure and is hardly influenced by weather; however, it is difficult to distinguish spring wheat and grass due to the similarity of both canopy structures during the major growth cycle. In order to resolve this problem, the present study proposed a method to extract spring canola and wheat by combining Radarsat-2 and Landsat-8 images based on Google Earth Engine. First, spring canola, forest, water and spring wheat and grass (both were regarded as one object) were extracted from Radarsat-2 image. Second, the cropland was extracted from Landsat-8 image. Third, synthetic mapping was carried out to achieve spring canola and wheat extraction. The result demonstrates that spring canola and wheat were successfully extracted with an overall accuracy of $96.04 \%$.

Keywords: Google Earth Engine, Landsat-8, Radarsat2, spring canola, spring wheat.

SPRING canola and wheat are important global food and oil crops ${ }^{1}$. It is important to obtain accurate crop planting area information to predict food pricing and food security $^{2,3}$. Remote sensing technology can provide accurate crop condition information across large areas and deliver timely information on products within seasons ${ }^{4-8}$. Research (including LAI, and biomass or yield estimation) on spring canola and wheat based on remote sensing technology has been successfully carried out ${ }^{9-11}$. For example, a normalized difference yellowness index, computed from green and blue wavebands of the moderateresolution imaging method of spectroradiometer (MODIS) data, was used to estimate yield of spring canola ${ }^{12}$. The correlation between Radarsat-2 and the dry crop biomass from spring canola and wheat was studied and it was found that spring wheat biomass had lower correlation with all Synthetic Aperture Radar (SAR) parameters compared to spring canola ${ }^{4}$.

*For correspondence. (e-mail: wumq@radi.ac.cn; niuzheng@radi.ac.cn)
However, several problems still remain when extracting spring canola and wheat in high latitude areas. These issues mostly include: (1) The monographic study on remotely sensed mapping of spring canola and wheat was insufficient, especially at high latitudes within complex environments. (2) Spring canola and wheat have the same growth cycle and their spectral characteristics are similar in the major growth season. Thus, optical images hardly distinguish between crops. (3) Importantly, spring canola and wheat spectral characteristics are different during the spring canola flowering period ${ }^{10}$. At high latitude areas, the flowering period is very transitory (generally less than a month) and it is rainy throughout the growth season. Therefore, it is difficult to acquire sufficient and high-quality optical images that distinguish the two crops. Although MODIS has a revisit time of one day, its spatial resolution is less than $250 \mathrm{~m}$, leading to low classification accuracy so the crop boundary could not be detected by this method. (4) SAR images are hardly influenced by weather and are sensitive to the shape and/or structure of plant stems and leaves ${ }^{4,13-16}$. However, it is difficult to identify spring wheat from grassy weeds because their stem, leaf shape and structure are similar.

In order to resolve these problems, a new method to extract spring canola and wheat by combining Radarsat-2 and Landsat-8 images was proposed. The work flow included three main steps: (1) the main objects were extracted using Radarsat-2 images; (2) cropland was extracted using Landsat- 8 images and Google Earth Engine ${ }^{17-19}$; (3) both classification results were combined to create a comprehensive map. The novel methods took full advantage of the features of both Landsat- 8 and Radarsat- 2 images.

The study area was a Radarsat- 2 extent with an approximate area of $27 \mathrm{~km} \times 27 \mathrm{~km}$ located at Shangkuli Farm within Inner Mongolia, Autonomous Region of China and is shown in Figure 1. The major crops are spring canola and wheat and their growth season (mainly from June to August) is transitory, meaning there is only one crop growth cycle for each year. The site is situated within a cold temperate zone with continental monsoons and short summers and long winters. The average summer temperature is about $19^{\circ} \mathrm{C}$ with an average annual temperature of about $1.6^{\circ} \mathrm{C}$. The average annual precipitation is about $1200 \mathrm{~mm}$.

The Google Earth Engine (GEE) is an advanced cloudbased platform for planetary-scale geospatial and remotely sensed data analysis. It combines petabyte-scale archives of publicly available remotely sensed imagery and other data, Google-scale storage and processing power as well as Google's computational infrastructure optimized for parallel processing of geospatial data. GEE also has APIs for JavaScript and Python for rapid prototyping and visualization of complex spatial analyses (https://developers. google.com/earth-engine/).

Applications of Earth Engine have included production of Google's cloud-free $15 \mathrm{~m}$ base map of Earth, 


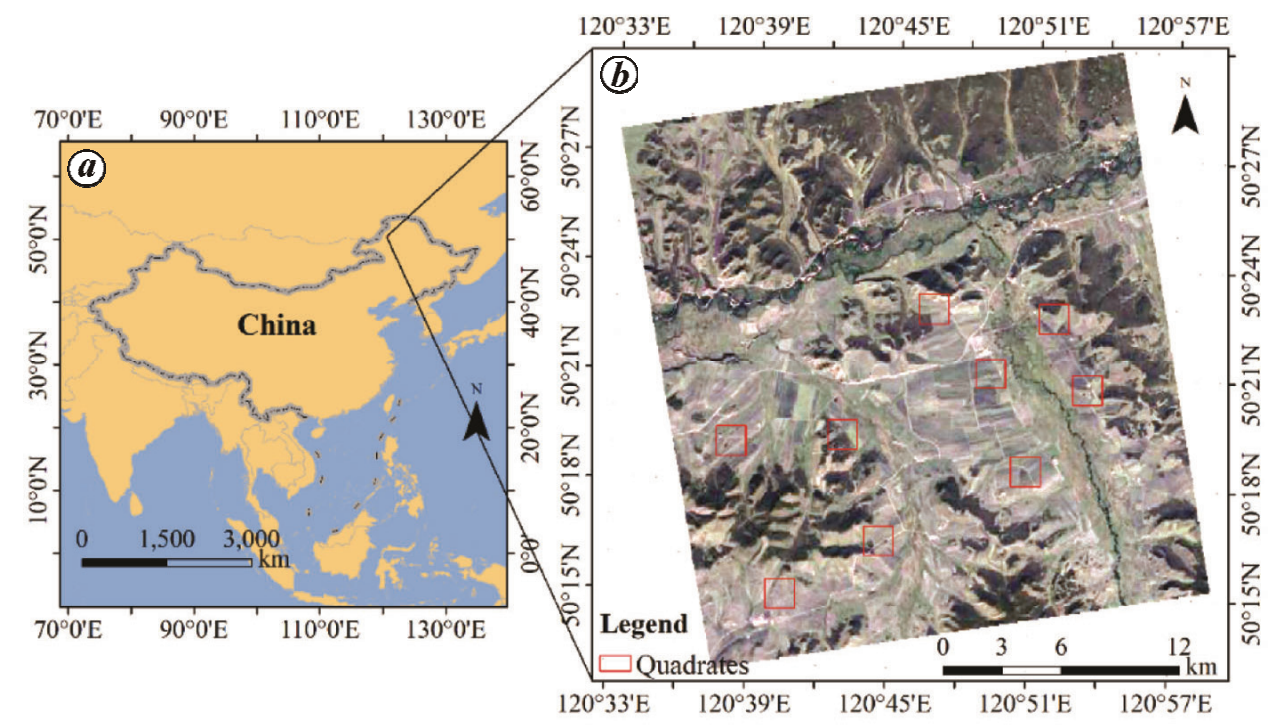

Figure 1. $\boldsymbol{a}$, Location of the study area. $\boldsymbol{b}$, A Google Earth image of the study area acquired on 2016 . The red rectangles represent the quadrates used to assess classification accuracy.

global-scale multi-decadal time-lapse animations, numerous large and small analyses by scientists from a range of academic, government and non-governmental institutions, and focused studies for detecting deforestation, classifying land cover and land cover change, estimating biomass, urban mapping and species habitat modelling ${ }^{17,20-22}$.

The Radarsat-2 satellite was successfully launched in December 2007 and its mission design and construction represented a significant evolution from Radarsat-1, with new capabilities designed to ensure Canada's continued leadership in the SAR global marketplace ${ }^{23-25}$.

Five scenes of Radarsat- 2 remotely sensed data used in the study were full-polarimetric ( $\mathrm{HH}, \mathrm{HV}, \mathrm{VV}$ and $\mathrm{VH})$, single-look complex (SLC) C-band SAR images and were acquired on 23 May, 16 June, 10 July, 3 August and 27 August 2013. These images were processed by SENTINEL-1 Toolbox software (S1TBX) (downloaded from http://nest.array.ca/web/nest). First, the radiometric correction was applied to all the image data, based on radiometric parameters provided in the header files, and to output radar backscatter images (sigma zero, $\sigma^{0}$ ). Second, these images were geo-rectified based on the Shuttle Radar Topography Mission (SRTM) digital elevation map (DEM) using Range-Doppler terrain correction $^{26}$, when the pixel size was resampled by $15 \mathrm{~m} \times$ $15 \mathrm{~m}$. Third, a $7 \times 7$ Lee sigma filter (S1TBX default) was applied to each image to reduce speckle noise. Fourth, the backscattering coefficient (in $\mathrm{dB}$ ) images were acquired from the $\sigma^{0}$ images by the equation $10 \times \log _{10}\left(\sigma^{0}\right)($ ref. 27$)$.

The Landsat- 8 satellite was successfully launched on 11 February 2013. It carries a two-sensor payload, the Operational Land Imager (OLI) and the Thermal Infrared Sensor (TIRS) $)^{28-30}$. OLI is a multispectral image includ- ing 9 bands: deep-blue (wavelength $0.433-0.453 \mu \mathrm{m}$ ), blue $(0.450-0.515 \mu \mathrm{m})$, green $(0.525-0.600 \mu \mathrm{m})$, red $(0.630-0.680 \mu \mathrm{m})$, near-infrared (NIR) $(0.845-0.885 \mu \mathrm{m})$, short-wave infrared (SWIR1) $(1.560-1.660 \mu \mathrm{m})$, SWIR2 $(2.100-2.300 \mu \mathrm{m})$, pan $(0.500-0.680 \mu \mathrm{m})$ and cirrus $(1.360-1.390 \mu \mathrm{m})$. The resolution of the pan band is $15 \mathrm{~m}$, while other bands are $30 \mathrm{~m}$. The Landsat- 8 data has a 16-day repeat cycle $^{30}$. All the Landsat-8 data (nine scene images in the study are a taken from 1 April to 30 October) used in the study come from the GEE Image Collection 'LANDSAT/LC8_L1T_TOA'. These images were the top-of-atmosphere reflectance images based on Level 1 terrain-corrected (L1T) products of United States Geological Survey (USGS) ${ }^{30}$. The Landsat- 8 multispectral images were fused with the pan band using HSV pan sharpening method to improve their spatial resolution to $15 \mathrm{~m}$.

NDVI and NDWI were the image products (derived from Landsat-8 data) required for the study. NDVI and NDWI were computed on GEE according to the flowing equation respectively ${ }^{27,31,32}$

$$
\begin{aligned}
& \text { NDVI }=\left(\rho_{\text {nir }}-\rho_{\text {red }}\right) /\left(\rho_{\text {nir }}+\rho_{\text {red }}\right), \\
& \text { NDWI }=\left(\rho_{\text {green }}-\rho_{\text {nir }}\right) /\left(\rho_{\text {green }}+\rho_{\text {nir }}\right),
\end{aligned}
$$

where $\rho_{\text {nir }}$ is the top-of-atmosphere reflectance of the NIR band, $\rho_{\text {red }}$ the top-of-atmosphere reflectance of the red band and $\rho_{\text {green }}$ is the top-of-atmosphere reflectance of the green band.

A SPOT-6 image, acquired on 3 September 2013, was a multispectral image consisting of blue, green, red and near infrared (NIR) bands (spatial resolution of $6 \mathrm{~m}$ ) in 


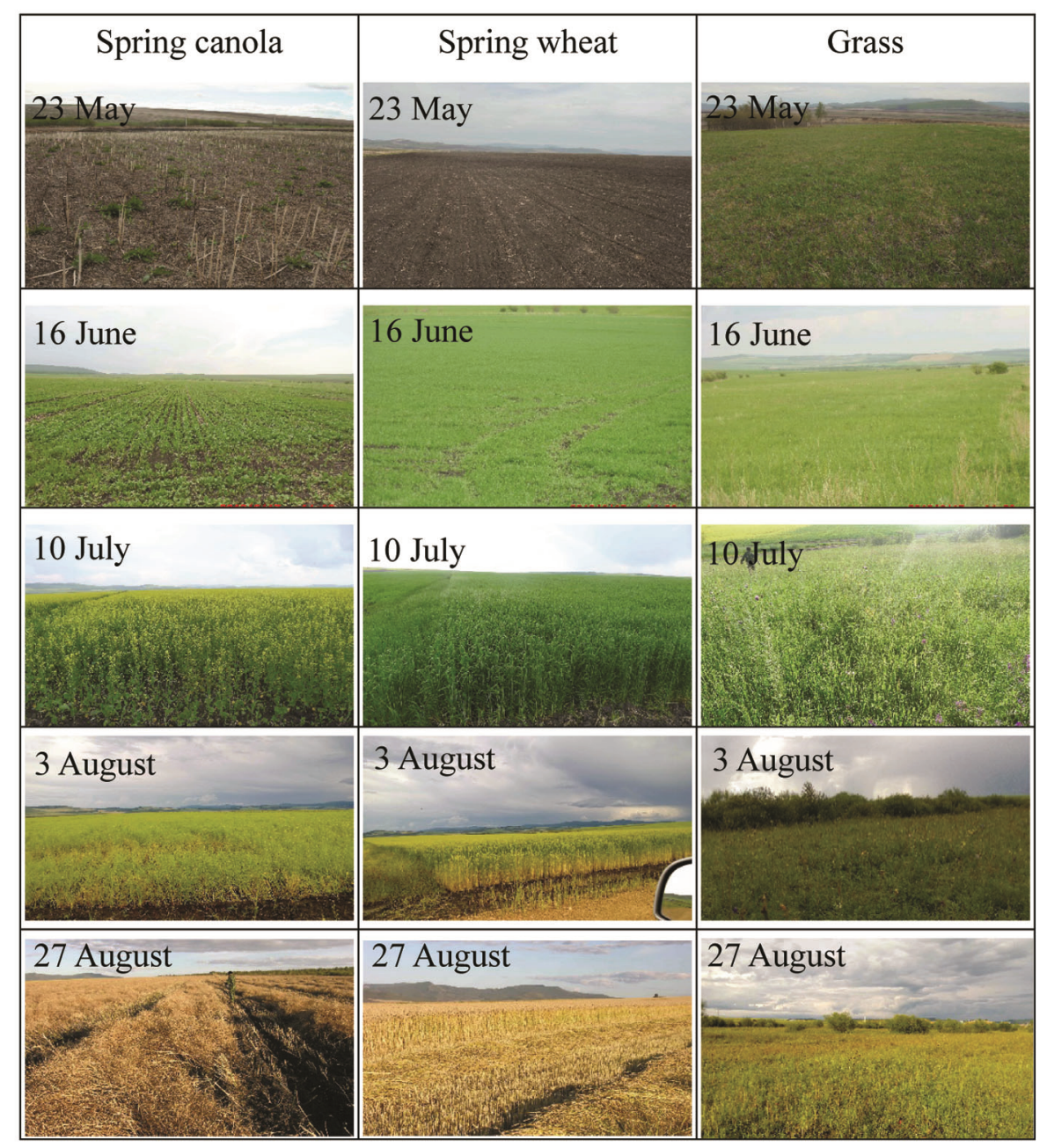

Figure 2. Field survey photos of spring canola, spring wheat and grass.

addition to a panchromatic image (spatial resolution of $1.5 \mathrm{~m})^{33}$. The image was ortho-rectified using highresolution DEM with a UTM zone $51 \mathrm{~N} / \mathrm{WGS}-84$ projection and RPC information. The multispectral image was fused with the panchromatic image to improve the resolution of the multispectral image to $1.5 \mathrm{~m}$ in ENVI software, which was then used to check the classification accuracy.

Auxiliary data included photos (indicating the phenological information) taken during five field surveys (Figure 1). As the Radarsat-2 images were acquired on 23 May, 16 June, 10 July, 3 August and 27 August 2013, the field survey dates were the same. We came to know the phenological information through these five-field surveys. The grass and forest had green leaves and the cropland, on 23 May 2013, was just beginning to be ploughed and sowed (Figure 2). By 16 June 2013, the spring canola and wheat had grown leaves, but several of the existing crop-land areas had not yet been sowed. By 10 July 2013, the majority of spring canola was flowering with yellow flowers. By 3 August 2013, the spring canola and wheat foliage was maturing and turning yellow, and the grass had also begun to turn yellow. By 27 August 2013, most of the spring canola and wheat had been harvested.

The major objects in the study area were spring canola, spring wheat, grass, forest and water. The backscattering coefficient of the five objects in the time series (from 23 May to 27 August) are plotted in Figure 3. The backscattering coefficient of forest and water had no distinct fluctuant on the full-polarization image in the time series. The other three objects had distinct fluctuant due to their ground characteristics having distinct change trends within the time series. For example, the backscattering coefficient increased from 23 May to 3 August and decreased from 3 August to 27 August on the full-polarization image (Figure 2).

In Figure $3 a$, the backscatter characteristics of spring canola, spring wheat and grass were similar in the time series. However, the backscattering coefficient of spring canola was more than that of grass on 3 August. In Figure $3 \mathrm{~b}$, the backscattering coefficient of spring canola, spring wheat and grass was the minimum on 23 May within the time series (from 23 May to 3 August), and at a maximum on 3 August. Besides, the backscattering coefficient 

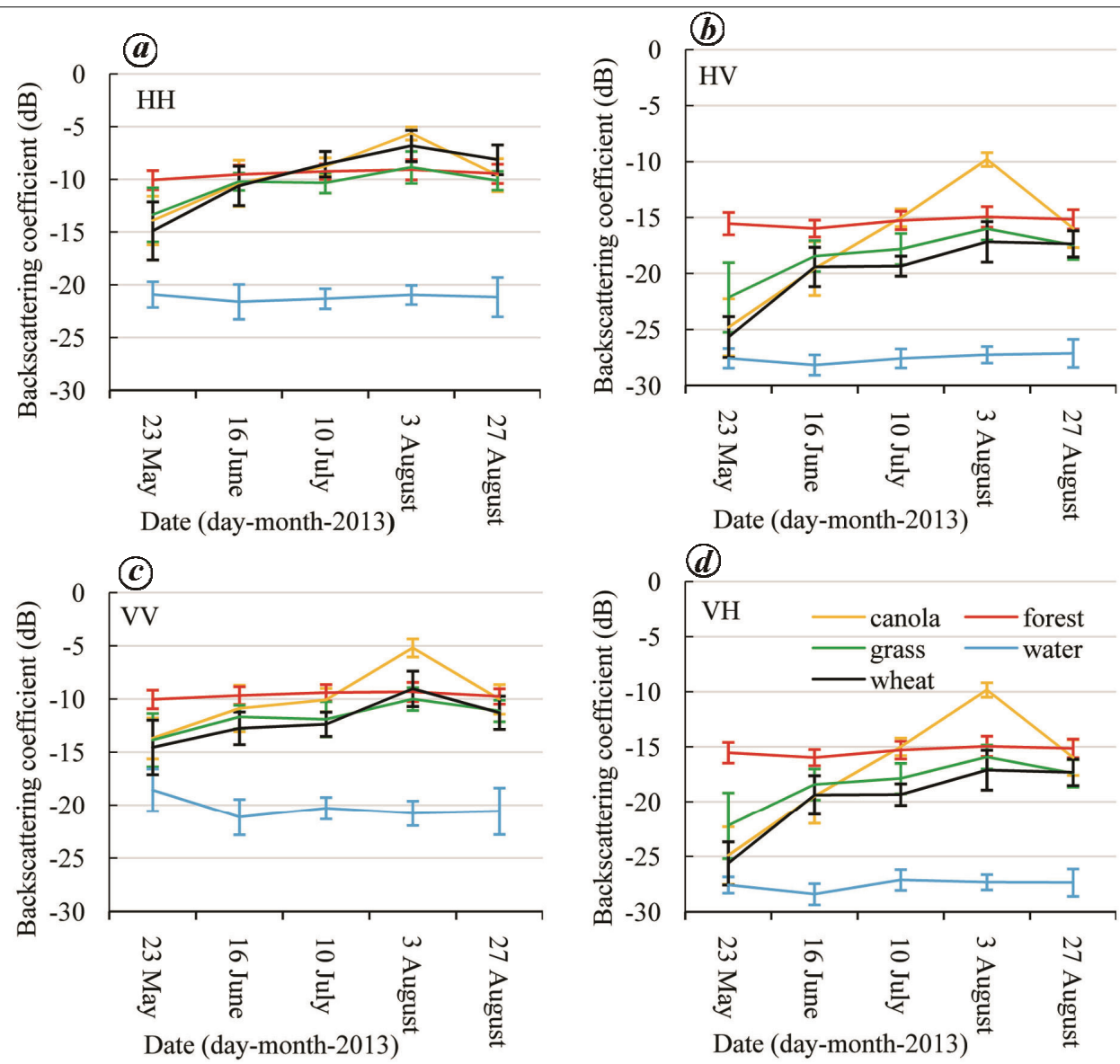

Figure $3 \boldsymbol{a}-\boldsymbol{d}$. The backscattering coefficient of different objects in different polarizations during 23 May to 27 August 2013. The legend of the four subgraphs was the same and hence only plotted in $\boldsymbol{d}$.

of spring canola was higher than that of spring wheat and grass on 3 August, and spring wheat and grass had similar backscatter characteristics. The backscatter characteristics of the five objects on $\mathrm{VH}$ was similar to that on $\mathrm{HV}$ due to the working principle of the Radarsat-2 sensor transmitting and receiving electromagnetic waves by a single station (Figure $3 b$ and $d$ ). Additionally, the backscatter characteristics of the five objects on VV was similar to that on $\mathrm{HH}$ (Figure $3 a$ and $c$ ).

Spring canola began to mature on 3 August, and produce long, skinny pods filled with seeds. The increase in biomass created a thick and rough canopy structure as the pods from neighbouring plants often intertwined with one another leading to a strong backscatter signal ${ }^{34}$.

It is difficult to distinguish between spring wheat and grass according to the Radarsat- 2 image, however, we regarded both objects as one to classify with the other three objects, namely, spring canola, forest and water. The workflow included four steps:

(1) Water extraction: Water extent was uncertain as it was influenced by rainfall. Therefore, the minimum value of the four $\mathrm{HH}$-images (from 16 June to 27 August) was selected for each pixel location to create a new image used to extract water. For example, on the four $\mathrm{HH}-$ images, each pixel location had four values, and the minimum was the required value. On the new image, a pixel was classified as water if its value was less than $-15 \mathrm{~dB}$, the threshold value was defined according to Figure $3 a$, and the classification layer was named as water-R layer.

(2) Spring canola extraction: A pixel was classified into spring canola if its value was more than $-13 \mathrm{~dB}$ on the $\mathrm{HV}$-image on 3 August and less than $-20 \mathrm{~dB}$ on the $\mathrm{HV}$-image on 23 May. The classification layer was named as spring canola.

(3) Forest extraction: A new image was created by subtracting the $\mathrm{HV}$-image on 23 May from the HV-image on 3 August. On the new image, the forest value was less than 3. Therefore, a pixel was classified into forest if its value was less than 3 on the new image and more than $-17 \mathrm{~dB}$ on the HV-image on 23 May. The classification layer was named forest layer.

(4) A pixel was classified into spring wheat and grass if it was not classified into water or spring canola or forest, and the classification layer was named wheat-grass layer.

Water, spring canola and forest were extracted from the Radarsat- 2 images based on a unique characteristic for each object respectively. Spring wheat and grass were 
classified into one classification because they could not be accurately and completely distinguished on the Radarsat-2 image.

The crop life-cycle ranged from 20 May to 10 September, and the forest and grass life-cycle ranged from 1 April to 30 October according to the survey information. Therefore, there was no vegetation between 1 April and 20 May and between 10 September and 30 October, and the forest and grass were green in the time series. Thus, the cropland NDVI average value (between 1 April and 20 May and between 10 September and 30 October) was small compared to that of forest and grass. For the crop life-cycle, between 20 May and 10 September, the cropland NDVI maximum value was approximate to that of forest and grass. The NDVI for the different time series was computed on GEE cloud platform. According to the characteristics mentioned above, a pixel was classified into cropland if its value was less than 0.18 on the average NDVI image between 1 April and 20 May and between 10 September and 30 October, and if it was more than 0.5 on the maximum NDVI image between 20 May and 10 September, the classification layer was named cropland.

The water extent was uncertain because it was influenced by rainfall. The Radarsat-2 time resolution was low

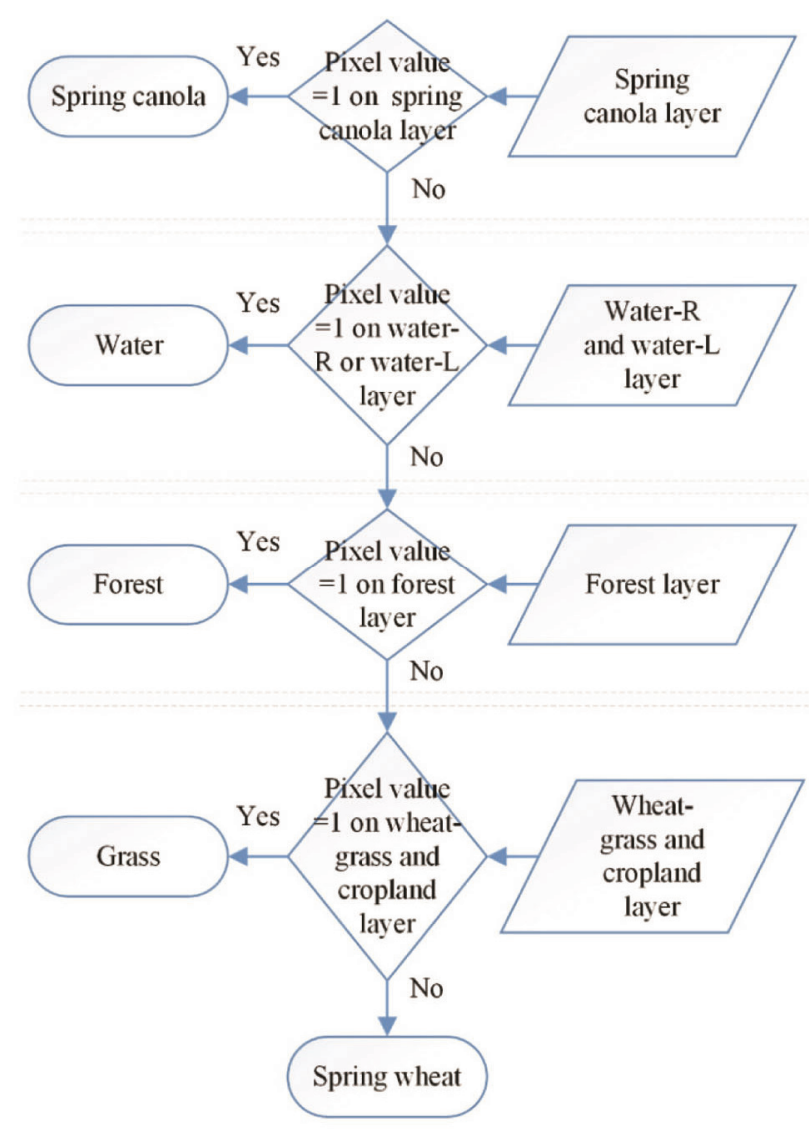

Figure 4. Flowchart of synthetic mapping. therefore some water may have not been observed by Radarsat-2. So, the maximum NDWI was computed on GEE cloud platform between 1 April and 30 October. A pixel was classified into water if its value was more than zero on the maximum NDWI image, and the classification layer was named water-L.

There were six classification layers, namely, water-R layer, spring canola layer, forest layer, wheat-grass layer (this fourth layer is mentioned previously), crop-land layer, and water-L layer (both these layers were outlined previously). The aim of synthetic mapping was to put the six layers into one map using a decision tree approach. The workflow is presented as a flowchart in Figure 4 with four decision layers. In the first decision layer, for the spring canola layer, a pixel value equal to one remained as a spring canola attribute and would not change in the next decision layer, or, the pixel was not spring canola. In the second decision layer, a pixel value equal to one on the water-R layer or the water-L layer would remain as the attribute of water and would not change in next decision layer, or, the pixel was not water. In the third decision layer, a pixel value equal to one on the forest layer would remain as a forest attribute and would not change in the next decision layer, or, the pixel was not forest. In the fourth decision layer, a pixel value equal to one on the wheat-grass layer and crop land layer would remain with an attribute of spring wheat, or, the pixel would be grass.

In order to objectively assess the classification accuracy, nine quadrats with areas of $1.5 \mathrm{~km} \times 1.5 \mathrm{~km}$ were randomly selected (Figure 1). These quadrats were artificially vectorized based on SPOT-6 multispectral image with a spatial resolution of $1.5 \mathrm{~m}$. Each vector-polygon attribute was amended according to the field survey data. These vector-quadrats were converted to raster images with a spatial resolution of $15 \mathrm{~m}$ to match that of the Landsat- 8 images. The raster images were used to check the classification accuracy using the confusion matrix model of the ENVI software, a commonly used method in remote sensing ${ }^{35}$. The parameters of the confusion matrix accuracy assessment included producer accuracy, user accuracy, omission and commission. Omission and commission were used to amend the area data of classification results according to the following equation

$$
A_{i a}=A_{i} \times\left(1+\delta_{i o}-\delta_{i c}\right)
$$

where $A_{i a}$ is the amended area of $i$ th classification, $A_{i}$ the area of $i$ th classification, $\delta_{i o}$ the omission of $i$ th classification and $\delta_{i c}$ is the commission of $i$ th classification.

The classification result is shown in Figure 5. The classification areas were counted with Albers Equal Area Conic projection, resulting in a spring canola area of $121.60 \mathrm{~km}^{2}$, spring wheat area of $73.84 \mathrm{~km}^{2}$, forest area of $242.53 \mathrm{~km}^{2}$, grass area of $237.02 \mathrm{~km}^{2}$ and water area 


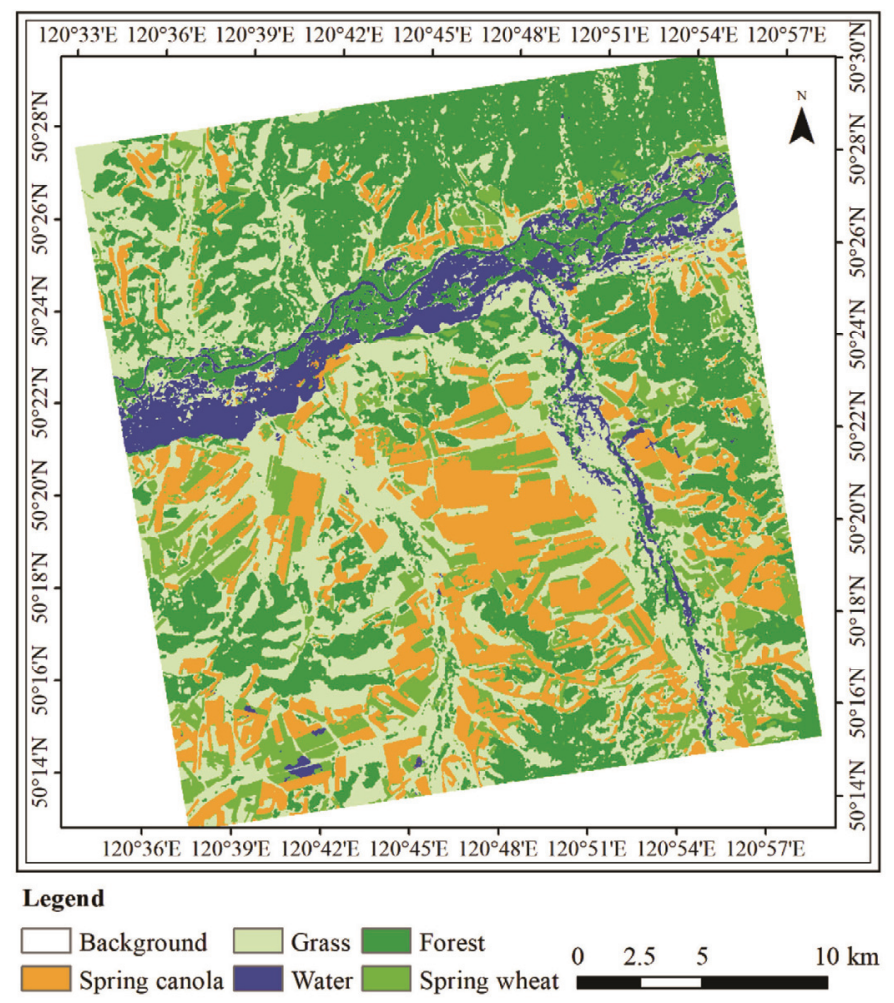

Figure 5. Classification result in the study area.

Table 1. Accuracy assessment objects

\begin{tabular}{lccrr}
\hline & Spring canola & Spring wheat & Grass & Forest \\
\hline Producer accuracy (\%) & 97.75 & 97.07 & 93.45 & 90.85 \\
User accuracy (\%) & 97.80 & 92.43 & 94.63 & 94.78 \\
Omission (\%) & 2.25 & 2.93 & 6.55 & 9.15 \\
Commission (\%) & 2.20 & 7.57 & 5.37 & 5.22 \\
\hline
\end{tabular}

of $41.50 \mathrm{~km}^{2}$. Figure 5 shows that the main crop spring canola was mainly distributed in the south of the main river. Compared to spring canola, the planting plots of spring wheat were more fragmented.

The overall accuracy was $96.04 \%$ with a kappa coefficient of 0.94 according to nine verification quadrats. The classification accuracy parameters of different objects are plotted in Table 1. We did not assess the classification accuracy of water due to its extent being variable. According to eq. (3), the amended spring canola area was $121.66 \mathrm{~km}^{2}$, the amended spring wheat area was $70.41 \mathrm{~km}^{2}$, the amended forest area was $252.06 \mathrm{~km}^{2}$, and the amended grass area was $239.82 \mathrm{~km}^{2}$.

The classification error is plotted in Figure 6 which only shows three quadrats, taking into account the length. The classification error was mainly distributed on the boundaries of surface features.

This study was a successful case that mapped spring canola and wheat with the same growth-cycle using
Radarsat- 2 and Landsat- 8 images. Radarsat- 2 had the superior ability to identify spring canola, forest, water and wheat-grass; however, it did not completely distinguish spring wheat and grass due to their similar canopy structure. Landsat- 8 had the superior ability to identify cropland according to specific phenological information. Thus, the intersection of both features meant we could accurately identify spring wheat.

GEE has strong processing capabilities for remotely sensed data including functionality to remove cloud, radiation correction, fusion and computing index. All Landsat-8 images were affected by cloud in the study area during the crop growth period. It would have taken several weeks to process the data to meet the requirements of this study using traditional methods. However, it only took less than one hour using GEE, which is one of the key factors in the success of this study. The larger the study area, the more advantages gained by using GEE.

It is very important to get accurate phenological vegetation information when extracting cropland at high latitudes. During the period between planting of a crop and harvesting, there is no green vegetation in the cropland, whereas forest and grass are growing and their leaves are green. Thus, it is vital to extract cropland from optical images during this period.

From the nine evenly distributed quadrats with areas of $1.5 \mathrm{~km} \times 1.5 \mathrm{~km}$ we were able to objectively assess the classification accuracy for this study. We believe it is not 

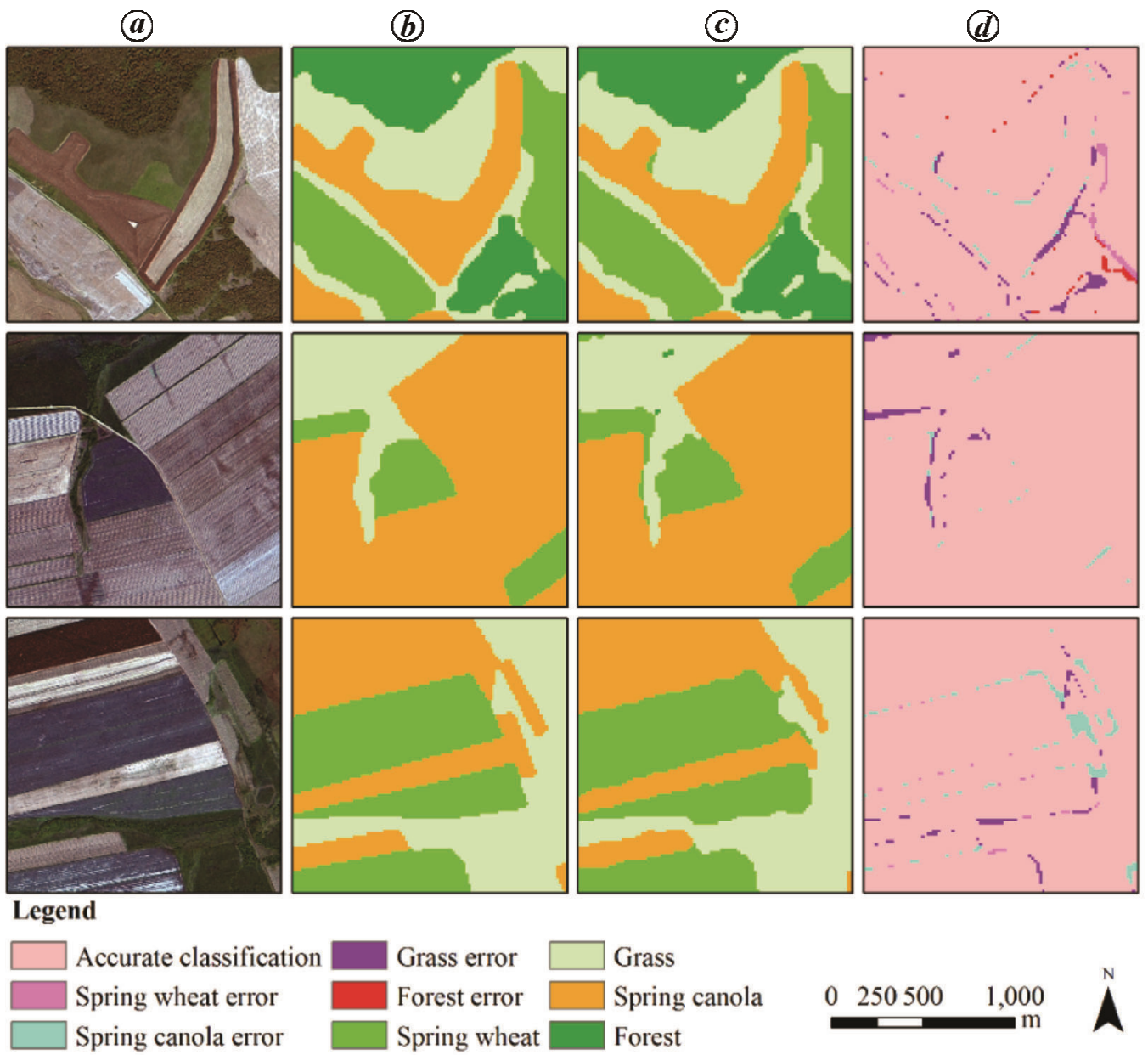

Figure 6. Distribution of classification error in quadrats. $\boldsymbol{a}$, SPOT-6 image; $\boldsymbol{b}$, Artificial interpretation ground truth classification based on SPOT-6 image and field survey data; $\boldsymbol{c}$, Classification results of the present study; $\boldsymbol{d}$, Accuracy distribution.

the last step work of accuracy assessment that produces the classification accuracy report. On the one hand, the classification accuracy indicates good or bad classification results. On the other hand, the classification accuracy should be used to amend the classification results. For example, the omission of spring wheat classification results of $2.93 \%$ meant that these pixels were not categorized as spring wheat, but they should have been. The ommission of spring wheat with classification results of $7.57 \%$ meant that these pixels were categorized as spring wheat, and they should not have been. Therefore, it is necessary to amend the areas of classification in agriculture remote sensing. However, this work was overlooked in previous studies $^{26,35-37}$.

At the high latitudes of China, spring canola, spring wheat, forest, grass and water were extracted from Radarsat- 2 and Landsat- 8 images with an overall accuracy of $96.04 \%$ in this study. Different object backscattering coefficients were similar on cross-polarization (HV and $\mathrm{VH}$ ) images, and cross-polarization was most sensitive to spring canola compared to HH or VV. Besides, the sow- ing and maturing periods were the key to identify spring canola from other objects at high latitudes. Although Radarsat-2 did not completely distinguish spring wheat and grass, it regarded both as one object to classify from other objects. This was the main contribution of Radarsat-2 to extract spring wheat. Although optical images are susceptible to cloud contamination, they are superior in their ability to identify cropland through GEE cloud platform.

Based on GEE cloud platform, we found making full use of the advantages of optical remote sensing and microwave remote sensing is an important way to improve the accuracy of rapid mapping of crops under complex conditions.

1. Kim, Y., Jackson, T., Bindlish, R., Hong, S., Jung, G. and Lee, K., Retrieval of wheat growth parameters with radar vegetation indices. IEEE Geosci. Remote Sci., 2014, 11, 808-812.

2. Cable, J., Kovacs, J., Jiao, X. and Shang, J., Agricultural monitoring in northeastern Ontario, Canada, using multi-temporal polarimetric Radarsat-2 data. Remote Sensing, 2014, 6, 23432371. 
3. Jiao, X., Kovacs, J. M., Shang, J., McNairn, H., Walters, D., Ma, B. and Geng, X., Object-oriented crop mapping and monitoring using multi-temporal polarimetric Radarsat-2 data. ISPRS J. Photogramm. Remote Sensing, 2014, 96, 38-46.

4. Wiseman, G., McNairn, H., Homayouni, S. and Shang, J. L., Radarsat-2 polarimetric SAR response to crop biomass for agricultural production monitoring. IEEE J-Stars, 2014, 7, 44614471.

5. Han, J. H. et al., Mapping above-ground biomass of winter oilseed rape using high spatial resolution satellite data at parcel scale under waterlogging conditions. Remote Sensing, 2017, 9, 238.

6. Mo, X. G., Chen, X. J., Hu, S., Liu, S. X. and Xia, J., Attributing regional trends of evapotranspiration and gross primary productivity with remote sensing: A case study in the north china plain. Hydrol. Earth Syst. Sci., 2017, 21, 295-310.

7. She, B., Huang, J. F., Zhang, D. Y. and Huang, L. S., Assessing and characterizing oilseed rape freezing injury based on MODIS and MERIS data. Int. J. Agric. Biol. Eng., 2017, 10, 143-157.

8. Wei, C. W., Huang, J. F., Wang, X. Z., Blackburn, G. A., Zhang, Y., Wang, S. S. and Mansaray, L. R., Hyperspectral characterization of freezing injury and its biochemical impacts in oilseed rape leaves. Remote Sensing Environ., 2017, 195, 56-66.

9. Jin, X. et al., Combined multi-temporal optical and radar parameters for estimating LAI and biomass in winter wheat using HJ and Radarsat-2 data. Remote Sensing, 2015, 7, 1325113272.

10. Sulik, J. J. and Long, D. S., Spectral indices for yellow canola flowers. Int. J. Remote Sensing, 2015, 36, 2751-2765.

11. Ortiz-Monasterio, J. I. and Lobell, D. B., Remote sensing assessment of regional yield losses due to sub-optimal planting dates and fallow period weed management. Field Crop Res., 2007, 101, 80-87.

12. Sulik, J. J. and Long, D. S., Spectral considerations for modeling yield of canola. Remote Sensing Environ., 2016, 184, 161-174.

13. Jiao, X. F., Kovacs, J. M., Shang, J. L., McNairn, H., Walters, D., Ma, B. L. and Geng, X. Y., Object-oriented crop mapping and monitoring using multi-temporal polarimetric Radarsat-2 data. ISPRS J. Photogramm. Remote Sensing, 2014, 96, 38-46.

14. Thompson, A. A. and McLeod, I. H., The Radarsat-2 SAR processor. Can. J. Remote Sensing, 2004, 30, 336-344.

15. Clavet, D., Toutin, T. and Kharbouche, S., Radarsat-2: A new source for topographic data acquisition in the Canadian Arctic without field control. Can. J. Remote Sensing, 2011, 37, 529534.

16. Tlili, A., Coulibaly, L., Hervet, E. and Adegbidi, H. G., Combination of spatial information and polarimetric mapping of forest compositions from SAR Radarsat-2 image. Can. J. Remote Sensing, 2012, 38, 324-335.

17. Patel, N. N. et al., Multitemporal settlement and population mapping from landsat using Google Earth Engine. Int. J. Appl. Earth Obs. Geoinf., 2015, 35, 199-208.

18. Tang, Z. et al., Assessing Nebraska play a wetland inundation status during 1985-2015 using Landsat data and Google Earth Engine. Environ. Monit. Assess., 2016, 188(12), 654.

19. Alonso, A., Munoz-Carpena, R., Kennedy, R. E. and Murcia, C., Wetland landscape spatio-temporal degradation dynamics using the new Google Earth engine cloud-based platform: Opportunities for non-speciatists in remote sensing. Trans. ASABE, 2016, 59, 1333-1344.

20. Dong, J. W. et al., Mapping paddy rice planting area in northeastern asia with Landsat 8 images, phenology-based algorithm and Google Earth Engine. Remote Sensing Environ., 2016, 185, 142-154.

21. Goldblatt, R., You, W., Hanson, G. and Khandelwal, A. K., Detecting the boundaries of urban areas in India: A dataset for pixel-based image classification in Google Earth Engine. Remote Sensing, 2016, 8, 634-652.
22. Xiong, J. et al., Automated cropland mapping of continental Africa using Google Earth Engine cloud computing. ISPRS J. Photogramm. Remote Sensing, 2017, 126, 225-244.

23. Morena, L. C., James, K. V. and Beck, J., An introduction to the Radarsat-2 mission. Can. J. Remote Sensing, 2004, 30, 221-234.

24. Ali, Z., Kroupnik, G., Matharu, G., Graham, J., Barnard, I., Fox, P. and Raimondo, G., Radarsat-2 space segment design and its enhanced capabilities with respect to Radarsat-1. Can. J. Remote Sensing, 2004, 30, 235-245.

25. Yang, Z., Shao, Y., Li, K., Liu, Q. B., Liu, L. and Brisco, B., An improved scheme for rice phenology estimation based on timeseries multispectral $\mathrm{HJ}-1 \mathrm{a} / \mathrm{b}$ and polarimetric Radarsat-2 data. Remote Sensing Environ., 2017, 195, 184-201.

26. Nguyen, D. B. and Wagner, W., European rice cropland mapping with SENTINEL-1 data: The mediterranean region case study. Water, 2017, 9, 392.

27. Tian, H., Li, W., Wu, M., Huang, N., Li, G., Li, X. and Niu, Z., Dynamic monitoring of the largest freshwater lake in China using a new water index derived from high spatiotemporal resolution SENTINEL-1a data. Remote Sensing, 2017, 9, 521-539.

28. Tollefson, J., Landsat 8 to the rescue. Nature, 2013, 494, 13-14.

29. Roy, D. P. et al., Landsat-8: Science and product vision for terrestrial global change research. Remote Sensing Environ., 2014, 145, 154-172.

30. Irons, J. R., Dwyer, J. L. and Barsi, J. A., The next Landsat satellite: The Landsat data continuity mission. Remote Sensing Environ., 2012, 122, 11-21.

31. Qiao, C., Luo, J. C., Sheng, Y. W., Shen, Z. F., Zhu, Z. W. and Ming, D. P., An adaptive water extraction method from remote sensing image based on NDWI. J. Indian Soc. Remote, 2012, 40, $421-433$.

32. McFeeters, S. K., Using the normalized difference water index (NDWI) within a geographic information system to detect swimming pools for mosquito abatement: a practical approach. Remote Sensing, 2013, 5, 3544-3561.

33. Li, W., Niu, Z., Liang, X. L., Li, Z. Y., Huang, N., Gao, S., Wang, C. and Muhammad, S., Geostatistical modeling using Lidarderived prior knowledge with Spot- 6 data to estimate temperate forest canopy cover and above-ground biomass via stratified random sampling. Int. J. Appl. Earth Obs. Geoinf., 2015, 41, 8898.

34. Cable, J. W., Kovacs, J. M., Jiao, X. F. and Shang, J. L., Agricultural monitoring in northeastern Ontario, Canada, using multi-temporal polarimetric Radarsat-2 data. Remote Sensing, 2014, 6, 2343-2371.

35. Hasituya and Chen, Z. X., Mapping plastic-mulched farmland with multi-temporal Landsat-8 data. Remote Sensing, 2017, 9, 557.

36. Bellon, B., Begue, A., Lo Seen, D., de Almeida, C. A. and Simoes, M., A remote sensing approach for regional-scale mapping of agricultural land-use systems based on NDVI time series. Remote Sensing, 2017, 9, 600.

37. Jiang, D., Huang, Y. H., Zhuang, D. F., Zhu, Y. Q., Xu, X. L. and Ren, H. Y., A simple semi-automatic approach for land cover classification from multispectral remote sensing imagery. PLoS ONE, 2012, 7(9), e45889.

ACKNOWLEDGEMENTS. This work was supported by the Strategic Priority Research Program of Chinese Academy of Sciences (XDA19030304) and the National Natural Science Foundation of China (41730107) and the Youth Innovation Promotion Association CAS (2017089).

Received 1 September 2017; revised accepted 15 June 2018

doi: $10.18520 / \mathrm{cs} / \mathrm{v} 116 / \mathrm{i} 2 / 291-298$ 